\title{
The state-of-the-art integrations and applications of the analytic hierarchy process
}

\author{
William $\mathrm{Ho}^{\mathrm{a}, *}$, Xin $\mathrm{Ma}^{\mathrm{b}}$ \\ ${ }^{a}$ Department of Management and Marketing, \\ The University of Melbourne, \\ 198 Berkeley Street, Carlton, Victoria 3010, Australia \\ ${ }^{\mathrm{b}}$ College of Engineering, Mathematics and Physical Sciences, \\ University of Exeter, \\ North Park Road, Exeter EX4 4QF, England, United Kingdom \\ *Corresponding author. Email: william.ho@unimelb.edu.au
}

\begin{abstract}
Because of its great flexibility and wide applicability, integrated analytic hierarchy process (AHP) approaches have been studied extensively for the last 20 years. This paper, as a follow-up study to Ho (2008), reviews the literature on the integrated AHP approaches and applications published between 2007 and 2016 and compares those studies with papers published during the previous decade, i.e., 1997-2006. Based on the 88 journal articles, five questions can be answered: (1) which type of integrated AHP approaches was paid most attention to? (2) Which application areas were integrated AHP approaches primarily applied to? (3) Which specific problems were integrated AHP approaches most commonly applied to? (4) What is the trend in publications regarding integrated AHP approaches? and (5) Which international journals were integrated AHP approaches most widely published in? Finally, some new applications of new AHP integrations are proposed to assist scholars in filling the literature research gaps.
\end{abstract}

Keywords: Analytic hierarchy process; integrations; applications; literature review. 


\section{Introduction}

Because of its simplicity, ease of use, and great flexibility, the analytic hierarchy process (AHP) has been studied extensively and used in nearly all applications related to multiple criteria decisionmaking (MCDM) since its development (Saaty, 1980). Because Ho (2008) observed in his literature review article that integrated AHP can result in a more realistic and promising decision than a standalone AHP, we focus only on integrated AHP approaches and conduct a follow-up literature review study to Ho (2008) to explore the new trends and advances of the integrated AHP and its applications from the perspective of operations/supply chain management from 2007 to 2016.

In the last decade, i.e., 2007-2016, five journal articles reviewing the literature of AHP have been published. Ho (2008) reviewed 66 journal articles published between 1997 and 2006. Ho concluded that the most popular integrated AHP approaches are the integrated AHP-GP and integrated AHP-QFD approaches and that the most widely applied area of the integrated AHP approaches is logistics. Transportation route selection, supplier/subcontractor selection, facility location selection, and scheduling plan selection are the most common problems addressed in logistics. Liberatore and Nydick (2008) reviewed 50 journal articles published between 1981 and 2006 that applied AHP to medical and health care decision-making. Those authors classified the articles into seven categories and determined that the AHP was most widely applied to project and technology evaluation and selection. Sipahi and Timor (2010) reviewed 232 journal articles published between 2005 and 2009 and concluded that applications of AHP are dominant in manufacturing. Supplier selection, supply chain evaluation, location selection, system selection or evaluation, and strategy evaluation are the most common problems addressed in manufacturing. In addition, those authors reported that the most frequently used integrated AHP approach is the integration of AHP and simulation. Subramanian and Ramanathan (2012) reviewed 291 journal articles published from 1999 to 2009 that applied the stand-alone and integrated AHP approaches in operations management. Their paper presented three major research findings. First, product and process design and supply chain management are the two most addressed decision themes. Second, applications of integrated AHP approaches in operations management occur more frequently than stand-alone AHP. Third, the applications of AHP in the manufacturing sector received more attention than in the service sector. Unlike the above four articles, Ishizaka and Labib (2011) reviewed the developments of AHP since its inception, including problem modeling, pairwise comparisons, judgment scales, derivation methods, consistency indices, incomplete matrices, synthesis of weights, sensitivity analysis, and group decisions.

Although the previously mentioned review articles make significant contributions to the literature of AHP, two significant knowledge gaps remain that motivated us to conduct this study. First, none of these review articles are sufficiently recent to include the many new studies published after 2009. Second, the previously mentioned review articles focus primarily on the commonly studied stand-alone and integrated AHP approaches during a certain period of time. None of these review articles provide a comparative analysis or analyze development trends. To fill these gaps, this paper presents a review 
of relevant journal articles appearing between 2007 and 2016 to analyze the integrations and applications of AHP and then compare these articles with those published between 1997 and 2006 (Ho, 2008).

There is no doubt that AHP is one of the most popular MCDM approaches (Ho, 2008). At the same time, AHP has been criticized considerably for the issue of rank reversals and the violation of a so-called condition of order preservation (COP). First, the issue of rank reversals means that the relative rankings of the other alternatives would change if an alternative is added or deleted (Belton and Gear, 1983). Since the early 1980s, there are two types of reactions about this issue. One group of researchers has suggested various modifications to avoid rank reversals in AHP (e.g., Schenkerman 1994; Wang and Elhag, 2006). Maleki and Zahir (2013) reviewed 61 scholarly papers from 18 journals on AHP methodologies and rank reversals. Another group of researchers has defended that rank reversal is an intrinsically legitimate phenomenon not only because the measurements are made in relative terms but also it has been observed to occur in practice. Therefore, there is no need to adjust AHP to avoid rank reversals (Forman, 1993; Saaty, 1994; Vargas, 1994; Millet and Saaty, 2000; Saaty, 2013).

Second, Bana e Costa and Vansnick (2008) criticized that the eigenvector method in AHP, used for deriving priorities, violates the COP: "For all alternatives $x_{1}, x_{2}, x_{3}, x_{4}$, such that $x_{1}$ dominates $x_{2}$ and $x_{3}$ dominates $x_{4}$, if the evaluator's judgments indicate the extent to which $x_{1}$ dominates $x_{2}$ is greater than the extent to which $x_{3}$ dominates $x_{4}$, then the vector of priorities $w$ should be such that not only $w\left(x_{1}\right)>$ $w\left(x_{2}\right)$ and $w\left(x_{3}\right)>w\left(x_{4}\right)$ (preservation of order of preference) but also that $w\left(x_{1}\right) / w\left(x_{2}\right)>w\left(x_{3}\right) / w\left(x_{4}\right)$ (preservation of order of intensity of preference)" (Saaty, 2013). Wang et al. (2009) used the concept of overall judgments to re-examine Bana e Costa and Vansnick's numerical examples, and revealed that Bana e Costa and Vansnick's criticism is invalid. Kulakowski (2015) argued that Bana e Costa and Vansnick's criticism is not the inherent problem of the prioritization procedure followed in AHP. Instead, the problem is due to the inconsistencies between elements of the pairwise comparison matrix, which is not detected by the inconsistency measurement used for the matrix as a whole (Kulakowski, 2015).

The remainder of the paper is organized as follows: Section 2 provides an introduction to the research methodology. Section 3 presents various integrated AHP approaches and their applications. Section 4 discusses the observations and compares this paper's conclusions with observations in Ho (2008). Section 5 proposes future research directions. Finally, Section 6 concludes the paper.

\section{Research methodology}

Because this paper is a follow-up literature review to Ho (2008), which reviewed journal articles published between 1997 and 2006, we will focus on journal articles published from 2007 to 2016. The research methodology is illustrated in Figure 1. First, the search term was defined. A title/abstract/keyword search with the term “Analytic Hierarchy Process” was used in the search process. Second, various academic databases were utilized to identify the journal articles, including EBSCOhost, 
Emerald, IEEExplore, Ingenta, Metapress, ProQuest, ScienceDirect, Springer, Taylor and Francis, and Wiley. To achieve the highest level of relevance, only peer-reviewed articles written in English and published in international journals were selected; conference papers, master's and doctoral dissertations, textbooks, book chapters, and notes were excluded from this review. Third, several criteria were determined and used to filter the articles. Regarding the criteria, abstracts of articles were examined to determine whether the article addressed integrated AHP approaches and applications. Note that articles simply suggesting other approaches to modify AHP, such as prioritizing divergent intangible alternatives (Saaty and Shang, 2011), improving the consistency ratio of the pairwise comparison matrix (Ergu et al., 2011), mitigating judgment contradiction (Kou et al., 2014), and modifying the priority vector derivation (Kou and Lin, 2014), do not meet the criteria because they lack of real-world applications. In addition, because thousands of articles have been published in the last decade, we focused on those articles published in international journals with high ranking, including $\mathrm{A} / \mathrm{A}^{*}$ journals on the Australian Business Deans Council (ABDC) journal list, and/or 3/4/4 journals on the Association of Business Schools (ABS) journal list in the United Kingdom. This filtering criterion would let researchers and practitioners learn about the prominent and state-of-the-art integrated AHP approaches and applications. Articles that did not meet one of these filtration criteria were excluded. Fourth, the reference lists of the shortlisted articles were carefully evaluated to ensure that no other articles of relevance were omitted in the search. Finally, the content of each article was thoroughly reviewed to ensure that the article fit into the context of integrated AHP approaches. This analysis resulted in 88 journal articles.

\section{Integrated AHP approaches and applications}

\subsection{Integrated AHP and fuzzy set theory}

Fuzzy set theory has been widely used in conjunction with AHP because fuzzy set theory enables decision-makers to render interval judgments and consider uncertainty or fuzziness. Twenty articles applied the integrated AHP and fuzzy (AHP-fuzzy) approach, as shown in Table 1. The articles can be classified into five categories: supplier evaluation and selection, product/process evaluation and selection, business information system assessment, project assessment, and others.

A number of researchers applied the integrated AHP-fuzzy approach to supplier evaluation and selection. Chan and Kumar (2007) and Chan et al. (2008) applied the integrated AHP-fuzzy approach to evaluate and select global suppliers with risk considerations for a hypothetical case. Other groups of researchers demonstrated the applications of the integrated AHP-fuzzy approach with real cases, including the textile industry (Wang et al., 2008), liquid crystal displays (LCD) manufacturing (Lee, 2009), the automotive industry (Kahraman et al., 2010), and the food industry (Rezaei and Ortt, 2013).

Several scholars applied the integrated AHP-fuzzy approach for product/process evaluation and selection in the manufacturing industry, including in the casting process and in producer evaluation and selection (Akarte and Ravi, 2007), sofa design evaluation and selection (Ma et al., 2007), rapid tooling 
process evaluation and selection (Nagahanumaiah et al., 2007), equipment maintenance strategy evaluation and selection (Wang et al., 2007), and statistical process control (SPC) implementation strategy evaluation and selection (Huang et al., 2009).

Regarding the business information system assessment, Kreng and Wu (2007) applied the integrated AHP-fuzzy approach to evaluate the performance of a knowledge portal system to improve the competitiveness of the Taiwanese stone industry. Sarfaraz et al. (2012) adopted the integrated AHPfuzzy approach to assess the customization options of an enterprise resource planning (ERP) system. Liang (2015) applied the integrated AHP-fuzzy approach to measure the performance of interorganizational information systems for the Taiwanese telecommunications industry.

With respect to project assessment, three groups of researchers applied the integrated AHP-fuzzy approach to evaluate and select projects, including knowledge management projects for a Taiwanese LCD manufacturing company (Wang and Chang, 2007), a government-sponsored industrial technology development program assessment in Taiwan (Huang et al., 2008), and a transportation project assessment in the United States (Arslan, 2009).

Three additional applications of integrated AHP-fuzzy approach cannot be classified in the above categories. Chu et al. (2007) assessed the performance of organizational transformation by Communities of Practices using the integrated AHP-fuzzy approach. Wang et al. (2012) developed a risk assessment model based on the integrated AHP-fuzzy approach that can analyze the aggregative risk of implementing green initiatives in the fashion supply chain. Third, van de Kaa et al. (2014) proposed the integrated AHP-fuzzy approach to model the process of technology standard selection.

\subsection{Integrated AHP and data envelopment analysis}

Seven articles applied the integrated AHP and data envelopment analysis (AHP-DEA) approach as shown in Table 2. These articles can be classified into four groups. First, two articles used the output of AHP as the input of the DEA. Korpela et al. (2007) studied the warehouse evaluation and selection problem using the integrated AHP-DEA approach. The AHP was used first to evaluate the performance level of alternative warehouses. The AHP-derived performance weightings were then passed to the DEA model to measure the warehouses' efficiency. Lin et al. (2011) applied the integrated AHP-DEA approach to evaluate the economic performance of 31 local governments in China. The AHP was used first to determine the weighted values of 31 local governments or decision-making units (DMUs) with respect to two qualitative variables. After that, the weighted values were used in the DEA model in conjunction with eight other quantitative variables to measure the relative efficiency of 31 DMUs.

Second, Sevkli et al. (2007) embedded the DEA into the AHP to select suppliers for a Turkish company operating in the appliance industry. In this approach, the DEA method derives local weights from a given judgment matrix and aggregates local weights to obtain overall weights. Each row and column of the pairwise matrix is assumed to be a DMU and an output, respectively. The efficiency scores are calculated using the DEA method and may be interpreted as the local weights of the DMUs. 
Third, Sueyoshi et al. (2009) combined the results of AHP and DEA to address the critical business unit evaluation and selection problem in a rental car company. In this approach, the AHP was used to process the qualitative information provided by past audits and management's experiences and judgments. The DEA model was deployed to measure quantitative data provided by the accounting department and the fleet information system. Finally, subjective (AHP) and objective (DEA) results were combined to determine the urgency and efficiency scores of each store.

Fourth, Wang et al. (2008), Wang and Chin (2009), and Mirhedayatian and Saen (2011) demonstrated that the integrated AHP-DEA approach for weight derivation and aggregation in the AHP was flawed and sometimes produced counterintuitive priority vectors for inconsistent pairwise comparison matrices, which renders its application quite restrictive. The researchers revised the integrated AHP-DEA approach to overcome these drawbacks with the aid of research fellow recruitment (Wang et al., 2008) and university president recruitment (Wang and Chin, 2009; Mirhedayatian and Saen, 2011) examples.

\subsection{Integrated AHP and mathematical programming}

Seven articles applied the integrated AHP and mathematical programming approaches as shown in Table 3, including goal programming (GP), mixed integer linear programming (MILP), dynamic programming (DP), linear programming (LP), and multi-objective linear programming (MOLP). In these approaches, the AHP evaluates and quantifies the relative importance of criteria and alternatives. The AHP-derived weights are then incorporated into the objective function or constraints of a mathematical programming model.

\subsubsection{Integrated AHP-GP approach}

Kull and Talluri (2008) utilized an integrated AHP-GP approach to evaluate and select suppliers with regard to risk factors and product life cycle considerations. In the proposed approach, the AHP was used to assess suppliers using the risk criteria and to derive risk scores. The GP model was then constructed to evaluate alternative suppliers based on multiple risk goals and various hard constraints. Anzar et al. (2011) proposed the integrated AHP-GP approach for agricultural asset valuation in the La Ribera district, Valencia. First, the AHP was used to evaluate alternative assets with respect to tangible and intangible information. Second, the GP was applied to capture the information provided by the scarce information and the attitude of the appraiser in the valuation process.

\subsubsection{Integrated AHP-MILP approach}

Kengpol (2008) proposed an integrated AHP-MILP approach to a design logistics distribution network for Greater Mekong Subregion countries. The AHP was used to determine customers' priorities and the distribution center operator's perspective on logistics distribution network design alternatives. 
The MILP model was then formulated to integrate priorities to minimize the total transportation costs with maximum satisfaction.

Similar to Kengpol (2008), Validi et al. (2014) also applied the integrated AHP-MILP approach to a logistics distribution network design. The major difference was that Validi et al. (2014) considered a low-carbon/green distribution system. First, the AHP was used to determine the decision-maker's preferences on various types of vehicles with respect to carbon emissions minimization. Then, the MILP model with green constraints was constructed to determine the optimal path and vehicle types.

\subsubsection{Integrated AHP-DP approach}

Mafakheri (2011) applied the integrated AHP-DP approach to the supplier selection and order allocation problem. First, the AHP was employed to evaluate potential suppliers and determine supplier ranking. The AHP-based supplier rankings were then incorporated into the DP model to determine the optimal order quantity with the objectives of maximizing a utility function and minimizing the total supply chain costs in a hypothetical case.

\subsubsection{Integrated AHP-LP approach}

Ishizaka and Labib (2014) developed the integrated AHP-LP approach for disaster assessment and effective resource allocation using the case of the Bhopal disaster. First, the AHP was deployed to assess the criticality of any event that may lead to a disaster. Then, the LP model was formulated to calculate the optimal allocation of available funds to avoid that disaster.

\subsubsection{Integrated AHP-MOLP approach}

Quezada and López-Ospina (2014) applied the integrated AHP-MOLP approach to design a strategy map of a balanced scorecard for a fishing company. The AHP was used to establish the importance of cause-effect relations within a strategy map. Then, the MOLP was formulated to minimize the number of selected relations and maximize the total importance of the selected relations.

\subsection{Integrated AHP and quality function deployment}

Five articles applied the integrated AHP and quality function deployment (AHP-QFD) approach as shown in Table 4. There were two commonalities among all of the articles. First, three houses of quality (HOQ) were proposed in each of the articles. Second, AHP was used to quantify the relative importance ratings and the relation weightings in the HOQ. Specifically, Baramichai et al. (2007) applied the AHP-QFD approach to evaluate and select business practices to achieve agility in the supplier-buyer supply chain in a plastics manufacturing company. In this approach, the first HOQ related the business challenge to changes; the second HOQ linked the changes to change accommodations, and the third HOQ evaluated the business practices infrastructures with respect to the change accommodations. 
A group of researchers applied the AHP-QFD approach to evaluate and select suppliers in various sectors, including automotive (Ho et al., 2011), bioenergy (Scott et al., 2013; Scott et al., 2015), and carpet manufacturing (Dey et al., 2015). In their approaches, the first HOQ related the company stakeholders to stakeholder requirements; the second HOQ linked the stakeholder requirements to evaluating factors, and the third HOQ evaluated alternative suppliers with respect to the evaluating factors.

\subsection{Integrated AHP and simulation}

Five articles applied the integrated AHP and simulation (AHP-simulation) approach as shown in Table 5. These articles can be classified into three groups. First, two articles used the output of AHP as the input of the simulation. Ayağ (2007) studied the machine tool selection problem using the integrated AHP-simulation approach. First, the AHP was used to rank the machine tool alternatives. Then, a simulation generator was used to model the manufacturing organization, evaluate each alternative remaining from the AHP, and select the final alternative. Rabelo et al. (2007) applied the integrated AHP-simulation approach to evaluate value chain alternatives for a multinational construction equipment corporation. The simulation approach was used to model the value chain system at strategic, tactical, and operational levels and evaluate the value chain alternatives. The AHP was used to help the simulation perform group analysis and consider qualitative criteria such as political instability.

Second, some scholars integrated simulation into the AHP to help make decisions. Ahn and Choi (2008) applied the integrated AHP-simulation approach to select the most appropriate ERP system for a Korean home-shopping company. To enhance the fitness of AHP, the scholars applied the simulationbased approach to build a group consensus instead of forming point estimates that were aggregated from individual preference judgments. Sharma and Agrawal (2009) developed the integrated AHPsimulation approach to evaluate the performances of production control policies. Simulation programs were used to predict the performance of policies with different demand patterns. After that, the AHP was applied to calculate the weight of alternatives to show the effectiveness of the production system.

Third, Yaraghi et al. (2015) compared the performance of stand-alone AHP with the performance of the integrated AHP-Monte Carlo Simulation approach against a real world and reliable ranking of blogs (weblogs) at different levels of uncertainty. Their simulation results indicate that when the uncertainty in terms of variation extends beyond 0.24, the integrated AHP-Monte Carlo Simulation approach provides more precise rankings than the stand-alone AHP.

\subsection{Integrated AHP and other approaches}

Eight articles integrated the AHP with other approaches as shown in Table 6, such as real options (RO), the theory of constraints (TOC), the 2-Tuple linguistic representation model (2TLRM), Dempster-Shafer theory (DST), the orders of magnitude (OM), and rough set theory (RST) approaches. First, two groups of researchers applied the integrated AHP-RO approach. Angelou and Economides 
(2008) applied the approach to evaluate and prioritize information and communications technologies (ICT) infrastructure investment projects for a water supply and sewage company. In this approach, the projects were first ranked using RO analysis. Then, the AHP was used to consider both tangible and intangible factors. Tsai and Hung (2009a) applied the integrated AHP-RO approach to determine the dynamic pricing for a hypothetical case in Internet retailing. The RO techniques were used first to determine whether the price was worth changing the initial quota. After that, the AHP was deployed to determine the basic quotas and the basic quota increments.

Second, two teams of researchers applied the integrated AHP-TOC approach to product-mix decision-making. Ray et al. (2010) applied the approach first: the TOC identified the resource constraints, and the AHP determined the product rankings to maximize the product throughput in a fabrication industry. Wang et al. (2014) re-examined the approach of Ray et al. (2010), and argued that Ray et al.'s (2010) approach would not generate the optimal solution, using three examples. The authors clarified the cases in which the integrated AHP-TOC approach can and cannot output the optimal solution.

Third, four groups of scholars proposed other integrations. Dong et al. (2013) applied the integrated AHP-2TLRM approach to evaluate and select the most livable city. The 2TLRM was incorporated into the AHP to enable AHP decision-makers generate numerical scales individually. Yeo et al. (2010) applied the integrated AHP-DST approach to measure the effectiveness of container ports located in Northeast Asia. In this approach, the DST was incorporated into the AHP weight evaluation for eliminating uncertainty and adjusting the contradictory opinions of each group. Zhü et al. (2014) applied the integrated AHP-OM approach to help restructure the iron and steel industry in China. Specifically, 31 alternative locations were evaluated with respect to 15 criteria based on the current status of the industry and governmental policy to prioritize the ideal location for the industry. In this approach, the dummy pivot OM approach was used in conjunction with the AHP to increase the robustness of the final results even when another alternative (a dummy pivot) was added. Song et al. (2013) applied the integrated AHP-RST to evaluate and prioritize customer requirements of an industrial product-service system in a rotary oil-free air compressor manufacturing company. This approach combines the advantage of AHP in requirement evaluation structure and the strength of RST in manipulating vagueness and subjectivity.

\subsection{Integrated AHP and multiple approaches}

Thirty-six articles integrated the AHP with more than one method (AHP-multiple), as shown in Table 7. First, 26 of 36 articles incorporated the fuzzy set theory into the AHP with a variety of other approaches, including DEA (Tseng et al., 2009; Kou et al., 2010; Kamvysi et al., 2014), GP (Tsai and Hung, 2009b), integer linear programming (ILP) (He et al., 2012), LP (Kamvysi et al., 2014; Ulutas et al., 2016), MOLP (Li et al., 2008), multi-objective MILP (MOMILP) (Babić and Perić, 2014), QFD (Nagahanumaiah et al., 2008; Kamvysi et al., 2014), axiomatic design (AD) (Büyüközkan, 2012), 
Copeland (Piechnicki et al., 2015), evidential reasoning theory (ERT) (Yan et al., 2012), genetic algorithm (GA) (Aguilar-Lasserre et al., 2009), geometric mean (Piechnicki et al., 2015), grey relational analysis (GRA) (Samvedi et al., 2012; Pitcchipoo et al., 2013), the Kano model (Ghorbani et al., 2013), life cycle assessment (LCA) (Chan et al., 2013), preference ranking organization method for enrichment evaluations (PROMETHEE) (Rao and Patel, 2010; Avikal et al., 2014), scoring methods (Sun et al., 2008), a technique for order preference by similarity to ideal solution (TOPSIS) (Büyüközkan et al., 2008; Ghorbani et al., 2013; Samvedi et al., 2013; Kilic et al., 2014; Yayla, 2015; Dincer et al., 2016), and VIKOR (Ren and Lützen, 2015).

The majority of these 26 articles studied the supplier evaluation and selection problem (Büyüközkan et al., 2008; Tsai and Hung, 2009b; Kou et al., 2010; Büyüközkan, 2012; Ghorbani et al., 2013; Pitcchipoo et al., 2013; Babić and Perić, 2014; Yayla, 2015; Ulutas et al., 2016). The other problems studied included batch plant design (Aguilar-Lasserre et al., 2009), business performance assessment (Tseng et al., 2009), course design evaluation and selection (Kamvysi et al., 2014), cutting fluid evaluation and selection (Rao and Patel, 2010), disassembly line balancing (Avikal et al., 2014), ERP system evaluation and selection (Kilic et al., 2014), expert evaluation and selection (Sun et al., 2008), fuel evaluation and selection (Ren and Lützen, 2015), machine tool evaluation and selection (Samvedi et al., 2012), portfolio investment assessment (Dincer et al., 2016), product design evaluation and selection (Li et al., 2008; Yan et al., 2012; Chan et al., 2013), rapid tooling process evaluation and selection (Nagahanumaiah et al., 2008), supply chain risk assessment (Samvedi et al., 2013), total productive maintenance design (Piechnicki et al., 2015), and transshipment problems (He et al., 2012).

Ten articles applied the integrated AHP-multiple approaches without considering the fuzzy set theory. Among these ten articles, the DEA was most commonly used (Zhou and Chen, 2010; Falsini et al., 2012; Zhang et al., 2012; Kengpol et al., 2014; Kengpol and Tuammee, 2016), followed by mathematical programming approaches (Meza et al., 2009; Che and Chiang, 2012; Falsini et al., 2012; Kengpol et al., 2014), QFD (Partovi, 2007; Zhou and Chen, 2010; Chang, 2012), quantitative risk assessment (QRA) (Kengpol et al., 2014; Kengpol et al., 2016), activity-based costing (ABC) (Zhang et al., 2012), analytic network process (ANP) (Partovi, 2007), entropy (Freeman and Chen, 2015), GA (Che and Chiang, 2012), GRA (Chang, 2012), K-means algorithm (Meza et al., 2009), rough sets theory (RST) (Che and Chiang, 2012), and TOPSIS (Freeman and Chen, 2015).

Like the fuzzy-based, integrated AHP-multiple approaches mentioned above, the supplier evaluation and selection problem attracted the most attention (Che and Chiang, 2012; Falsini et al., 2012; Zhang et al., 2012; Freeman and Chen, 2015), followed by transportation route evaluation and selection (Kengpol et al., 2014; Kengpol et al., 2016), business process reengineering (Zhou and Chen, 2010), manufacturing flexibility evaluation and selection (Chang, 2012), manufacturing process evaluation and selection (Partovi, 2007), and power generation expansion planning (Meza et al., 2009). 


\section{Observations and discussions}

In this paper, 88 journal articles published between 2007 and 2016 that studied integrated AHP approaches were reviewed. The methods integrated with the AHP include fuzzy set theory, DEA, mathematical programming, QFD, simulation, and some others. These integrated AHP approaches and their applications are summarized in Tables 1-7. Based on the 88 journal articles, five questions can be answered: (1) Which type of integrated AHP approach received the most attention? (2) Which application areas were integrated AHP approaches most often applied to? (3) Which specific problems were integrated AHP approaches most commonly applied to? (4) What are the trends in publications regarding the integrated AHP approaches? and (5) Which international journals published the most papers on integrated AHP approaches? In addition to answering these questions, this paper also attempts to compare the findings with findings obtained during the period from 1997 to 2006, published in Ho (2008).

\subsection{The most popular integrated AHP approach}

The first question requires determining the most popular integrated AHP approach. Among the 88 journal articles, 52 articles integrated the AHP with a single method as listed in Tables 1-6, whereas 36 articles integrated the AHP with two or more methods (so-called integrated AHP-multiple approaches) as shown in Table 7. According to Tables 1-6, the most popular method integrated with the AHP is fuzzy set theory (20 of 52 articles), followed by DEA ( 7 articles), mathematical programming (7 articles), QFD (5 articles), simulation (5 articles), and some others (8 articles), including RO, TOC, 2TLRM, DST, OM, and RST.

According to Table 7, there are a wide variety of integrated AHP-multiple approaches. The majority of these studies integrated the AHP with two methods (31 of 36 articles), followed by three methods (4 articles) and four methods ( 1 article). Because there is no single dominating approach, we developed Table 8 to determine the most popular method applied in the integrated AHP-multiple approaches. Table 8 shows that the top 5 methods are fuzzy set theory (26 of 36 articles), followed by mathematical programming (10 articles), DEA (8 articles), TOPSIS (7 articles), and QFD (5 articles).

The above observations indicate that the integrated AHP-fuzzy approach attracted the most attention between 2007 and 2016. In addition, the fuzzy set theory was commonly used in conjunction with the AHP in the integrated AHP-multiple approaches. Forty-six of 88 articles integrated AHP with fuzzy set theory. The major reason is that the crisp pairwise comparison in conventional AHP is unable to tolerate vagueness or ambiguity. Therefore, fuzzy numbers and linguistic terms have been widely used in an uncertain pairwise comparison environment (Lee, 2009; Liang, 2015). Specifically, fuzzy set theory has the advantage of resembling human reasoning in its use of approximate information and uncertainty to address multi-criteria, decision-making problems when information is imprecise and incomplete (Chan and Kumar, 2007). 
Comparing the findings obtained over two decades (i.e., 1997-2006 vs. 2007-2016), first, the most popular integrated AHP approach changed completely. From 1997 to 2006, both the integrated AHP-GP and the integrated AHP-QFD approaches were the most popular, each studied in 16 of 66 articles (24\%) (Ho, 2008). From 2007 to 2016, only two of 88 articles applied the integrated AHP-GP approach (2\%) whereas the integrated AHP-QFD approach attracted a little more attention (5 of 88 articles, 6\%). The declination of applications and/or publications of both the integrated AHP-GP approach and the integrated AHP-QFD approach in prestigious journals is expected to be associated with the limitations of the AHP. Specifically, as mentioned in Section 3.3.1, Kull and Talluri (2008) applied the AHP to assess suppliers using the risk criteria and to derive risk scores, which were then used in the GP model to evaluate alternative suppliers based on multiple risk goals and various hard constraints. Kull and Talluri (2008) claimed that the major drawback of the AHP is its inability of handling the interdependence among various supplier failure events. By using the AHP, the authors assumed that the failure events are all independent, but not the case in real life situations. For example, poor information systems may lead to quality problems and delivery problems. For the integrated AHPQFD approach, Ho and his research team (Ho et al., 2011; Scott et al., 2013; Scott et al., 2015; Dey et al., 2015) applied the approach to capture holistic and conflicting requirements from all concerned stakeholders, and then translate to explicit and comparable evaluation criteria for strategic supplier selection and performance management. The major drawback of the approach is that the AHP process is very time-consuming especially when the number of stakeholder requirements and the number of evaluation criteria are large.

Second, the number of types of integration increased significantly. In 1997-2006, there were only five types of integration, including mathematical programming, QFD, meta-heuristics, SWOT, and DEA. From 2007 to 2016, if we focus on Tables 1-6, there were already 11 types of integration. There were 24 more methods integrated with the AHP, which were not identified in 1997-2006, such as 2TLRM, ABC, AD, ANP, Copeland, DST, Entropy, ERT, fuzzy set theory, geometric mean, GRA, Kmeans algorithm, Kano model, LCA, OM, PROMETHEE, QRA, RO, RST, scoring method, simulation, TOC, TOPSIS, and VIKOR.

\subsection{The most commonly studied application area}

The second question was to identify the most commonly studied application area. According to Table 9, there are 19 application areas, among which manufacturing has attracted the most attention, followed by logistics, government, higher education, utility, process, Internet, telecommunications, textiles and fashion, chemicals, food, agricultural, airlines, bakeries, construction, financial, fishing, iron and steel, and rental cars sectors.

According to Table 9, 35 of 88 articles applied the integrated AHP approaches to the manufacturing sector. The specific fields included air compressor manufacturing (Song et al., 2013), automotive manufacturing (Kull and Talluri, 2008; Kahraman et al., 2010; Kou et al., 2010; Ho et al., 
2011; Büyüközkan, 2012; Samvedi et al., 2012), carpet manufacturing (Dey et al., 2015), cutting-tool manufacturing (Ayağ, 2007), electronics manufacturing (Li et al., 2008; Zhang et al., 2012; Chan et al., 2013; Freeman and Chen, 2015), equipment manufacturing (Yan et al., 2012; Ghorbani et al., 2013), furniture manufacturing (Ma et al., 2007), LCD manufacturing (Wang and Chang, 2007; Huang et al., 2009; Lee, 2009; Tseng et al., 2009), mould manufacturing (Nagahanumaiah et al., 2007; Nagahanumaiah et al., 2008), plastics manufacturing (Baramichai et al., 2007), steel casting manufacturing (Akarte and Ravi, 2007), stone manufacturing (Kreng and Wu, 2007), TV manufacturing (Sevkli et al., 2007), and general manufacturing (Chan and Kumar, 2007; Chan et al., 2008; Sharma and Agrawal, 2009; Rao and Patel, 2010; Zhou and Chen, 2010; Mafakheri et al., 2011; Che and Chiang, 2012; Sarfaraz et al., 2012; Avikal et al., 2014). Among 35 articles, the fuzzy set theory was widely used in conjunction with AHP, including 11 integrated AHP-fuzzy approach and nine integrated AHPmultiple approaches.

Comparing the findings obtained from two separate decades (i.e., 1997-2006 vs. 2007-2016), first, the most commonly studied application area changed. From 1997 to 2006, logistics attracted the most attention with 21 of 66 articles (32\%) (Ho, 2008). From 2007 to 2016, logistics attracted much less attention, with only 10 of 88 articles (11\%) but nevertheless ranked second, just behind manufacturing (35 of 88 articles, 40\%), as mentioned above. Note that both manufacturing and logistics are the top two studied application areas over both decades. Second, the number of application areas increased. From 1997 to 2006, there were 14 application areas studied: logistics, followed by manufacturing, government, higher education, business, environment, military, agriculture, health-care, marketing, industry, service, sports, and tourism. From 2007 to 2016, there were 19 application areas studied. Among those areas, 14 application areas were not covered from 1997 to 2006, such as airlines, bakeries, chemicals, construction, financial, fishing, food, Internet, iron and steel, processing, rental cars, telecommunications, textiles and fashion, and utility sectors.

\subsection{The most commonly studied problem}

The third question was to discover the most commonly studied problem. According to Table 10, 21 problems were studied, among which the supplier evaluation and selection problem attracted the most attention, followed by performance assessment, strategy/policy evaluation and selection, distribution network optimization, process evaluation and selection, expert evaluation and selection, product design evaluation and selection, project/program evaluation and selection, equipment/tool evaluation and selection, location evaluation and selection, risk assessment, system evaluation and selection, product-mix evaluation and selection, batch plant design, business unit evaluation and selection, course design evaluation and selection, disassembly line balancing, dynamic pricing and revenue management, fuel evaluation and selection, power generation expansion planning, and value chain evaluation and selection. 
According to Table 10, 26 of 88 articles addressed the supplier evaluation and selection problem using integrated AHP approaches. The specific problems included agricultural machinery provider evaluation and selection (Ghorbani et al., 2013), apparel supplier evaluation and selection (Ulutas et al., 2016), automotive supplier evaluation and selection (Kull and Talluri, 2008; Kou et al., 2010; Ho et al., 2011; Büyüközkan, 2012), biomass supplier evaluation and selection (Scott et al., 2013; Scott et al., 2015), carpet supplier evaluation and selection (Dey et al., 2015), catering firm evaluation and selection (Wang et al., 2008), electronics supplier evaluation and selection (Zhang et al., 2012; Freeman and Chen, 2015), electroplating supplier evaluation and selection (Pitcchipoo et al., 2013), ERP provider evaluation and selection (Kahraman et al., 2010), flour supplier evaluation and selection (Babić and Perić, 2014), food supplier evaluation and selection (Rezaei and Ortt, 2013), global supplier evaluation and selection (Chan and Kumar, 2007; Chan et al., 2008), LCD manufacturing supplier evaluation and selection (Lee, 2009), logistics partner evaluation and selection (Büyüközkan et al., 2008; Falsini et al., 2012; Yayla, 2015), mobile phone supplier evaluation and selection (Tsai and Hung, 2009b), TV set manufacturing supplier evaluation and selection (Sevkli et al., 2007), and generic supplier evaluation and selection (Mafakheri et al., 2011; Che and Chiang, 2012). In the 26 articles, the fuzzy set theory was widely used in conjunction with AHP, including six integrated AHP-fuzzy approaches and eight integrated AHP-multiple approaches.

Comparing the findings obtained over two decades (i.e., 1997-2006 vs. 2007-2016), first, the most commonly studied problem changed. Between 1997 and 2006, transportation route selection or the distribution network optimization problem attracted the most attention with 11 of 66 articles (17\%) (Ho, 2008). Between 2007 and 2016, the distribution network optimization problem attracted much less attention, occurring in only 5 of 88 articles (6\%). Conversely, the supplier evaluation and selection problem attracted much more attention, 8\% (5 of 66 articles) from 1997 to 2006 vs. 30\% (26 of 88 articles) from 2007 to 2016. Supplier evaluation and selection has been regarded as one of the most important decision making problems in supply chain management (Goffin et al., 2006; Dey et al., 2015). Selecting and collaborating with strategic suppliers not only reduces the purchasing costs (Ghodsypour and O’Brien, 2001) and manufacturing costs (Narasimhan and Das, 1999) significantly, but also contributes in product quality (Su et al., 2009), product innovation (Dey et al., 2015), firm's flexibilities (Narasimhan and Das, 1999; Chiang et al., 2012), and supply chain agility (Chiang et al., 2012). Therefore, appropriate supplier selection improves supply chain performance. According to Table 10, 15 of 26 articles (58\%) addressed the supplier evaluation and selection problem using the fuzzy set theory based AHP approaches, including six integrated AHP-fuzzy approaches and nine integrated AHP-multiple approaches. It is believed that the fuzzy set theory based AHP approaches work very well in this domain. As Ho et al. (2011) highlighted, multiple perspectives from multiple stakeholders should be considered in order to facilitate effective and strategic supplier evaluation and selection. The fuzzy set theory based AHP approaches can support team based (i.e., multiple stakeholders) decision making processes when information (i.e., multiple perspectives) is imprecise and incomplete. 
Second, the number of problems studied decreased. From 1997 to 2006, there were 38 problems studied: transportation route selection, followed by product design evaluation and selection, supplier evaluation and selection, location evaluation and selection, etc. From 2007 to 2016, 21 application areas were studied. Fourteen of those problems were not addressed between 1997 and 2006, such as batch plant design, business unit evaluation and selection, course design evaluation and selection, disassembly line balancing, dynamic pricing and revenue management, equipment/tool evaluation and selection, expert evaluation and selection, fuel evaluation and selection, power generation expansion planning, product-mix evaluation and selection, risk assessment, strategy/policy evaluation and selection, system evaluation and selection, and value chain evaluation and selection.

\subsection{Trends}

The distribution of the 88 journal articles over the last decade is presented in Table 11. There are 22 articles more in the period from 2007 to 2016 than from 1997 to 2006. Notably, in this paper, we only focus on those articles published in international journals with high ranking, including $\mathrm{A} / \mathrm{A}^{*}$ journals on the Australian Business Deans Council (ABDC) journal list, and 3/4/4* journals on the Association of Business Schools (ABS) journal list in the United Kingdom.

Although there are more publications addressing the integrated AHP approaches in the highranking journals in the more recent decade, there is a decreasing trend in the use of integrated AHP approaches in the first five years of the decade (2007-2011) compared with the last five years (2012 to 2016), 48 vs. 40. In particular, according to Table 11, there is a significant decreasing trend in the use of AHP integration with one method from the first five years to the second five years, 36 vs. 16 . Conversely, the number of publications of AHP integration with multiple methods in the last five years is double the number in the first five years, 24 vs. 12. Based on the above observations, it is estimated that integrated AHP-multiple approaches will attract more attention.

\subsection{The most commonly published journal}

The international journals in which the integrated AHP approaches were published are listed in Table 12. There are 17 journals, among which the International Journal of Production Research ranks number one, followed by the International Journal of Production Economics, IEEE Transactions on Engineering Management, the European Journal of Operational Research, Omega, Journal of the Operational Research Society, Decision Support Systems, Supply Chain Management: An International Journal, Computers \& Operations Research, Computers in Industry, IEEE Transactions on Systems, Man, and Cybernetics - Part A: Systems and Humans, the International Journal of Logistics Management, Annals of Operations Research, the International Journal of Operations \& Production Management, Production Planning \& Control, Transportation, and Transportation Research Part D: Transport and Environment. 
Three journals must be highlighted based on the comparisons of the findings obtained over two decades (i.e., 1997-2006 vs. 2007-2016). First, the European Journal of Operational Research ranked number one with 8 of 66 articles (12\%) from 1997 to 2006, slightly reduced to 10\% (9 of 88 articles) from 2007 to 2016. Second, the ranking of the International Journal of Production Economics remains the same as the top two in two decades. The percentage of publications in this journal has increased slightly from 11\% (7 of 66 articles) from 1997 to 2006 to 14\% (12 of 88 articles) from 2007 to 2016. Third, the percentage of publications in the International Journal of Production Research has increased significantly from 3\% (2 of 66 articles) from 1997 to 2006 to 34\% (30 of 88 articles) from 2007 to 2016. With IEEE Transactions on Engineering Management, these four journals have published 61 of 88 articles (69\%). Therefore, it is expected that the integrated AHP-multiple approaches will appear more frequently in those four international journals.

\section{Future work}

Based on the observations in Section 4, room remains for integrated AHP approaches, particularly the integrations with multiple methods, to be published in high-ranking international journals. Therefore, in this section, some recommendations are directed to scholars regarding the new applications of the newly integrated AHP approaches.

First, supply chain risk management has been one of the "hot" research topics in the field of operations/supply chain management and has attracted significant attention from practitioners (Ho et al., 2015). Nevertheless, only three of 88 articles examined the risk assessment problem, as seen in Table 10. Conversely, according to Table 10, supplier evaluation and selection was the most commonly studied problem. However, the incorporation of both upstream and downstream risk mitigation strategies in supplier selection decisions has been under-studied (Ho et al., 2015). Therefore, we propose to apply the integration of AHP, multi-objective, mixed integer programming and simulation approaches to evaluate and select the optimal combination of supplier selection and risk mitigation strategies. The objectives are to minimize the total cost and maximize total reliability (i.e., risk minimization) in a stochastic multiple planning period.

Second, sustainable sourcing has been another current topic widely studied by both academics and practitioners. The focus of many studies, however, has been on the large international corporations; less is known regarding the small and medium-sized enterprises (SMEs) located in emerging economies. Although it is widely accepted that SMEs play a significant role in the economic development in the Asia-Pacific region, those businesses also exert considerable pressure on the environment collectively. Therefore, we propose to apply the integration of AHP, corporate social responsibility, total cost of ownership, and green initiatives to develop a holistic sustainability performance management model to evaluate sustainable SME suppliers in emerging economies. After that, a game model would design a procurement contract to maximize the mutual benefits of both manufacturers and suppliers, including profit maximization and carbon emissions minimization. 


\section{Conclusions}

This paper, as a follow-up study to Ho (2008), reviewed the literature on the integrated AHP approaches and applications published between 2007 and 2016 and compared the findings to studies published in the previous decade, i.e., 1997-2006. In addition to the searching and filtering criteria used in Ho (2008), this paper focused on those articles published in international journals with high ranking, including A/A* journals on the Australian Business Deans Council (ABDC) journal list, and/or 3/4/4* journals on the Association of Business Schools (ABS) journal list in the United Kingdom. This criterion would not only let researchers and practitioners learn about the prominent and state-of-the-art integrated AHP approaches and applications, but also provide researchers valuable insights of developing, applying, and publishing novel integrated AHP approaches in high-ranking journals.

The findings of this paper are summarized as follows. First, the integrated AHP-fuzzy approach replaced the integrated AHP-GP approach and the integrated AHP-QFD approach as the most popular integrated AHP approach in the period from 2007 to 2016. Second, this study observed that the manufacturing sector replaced logistics as the most popular application area. Consistent with Ho (2008), this study concluded that both manufacturing and logistics sectors remained the top two application areas to which the integrated AHP approaches were most frequently applied. Third, supplier evaluation and selection replaced distribution network optimization as the most commonly studied problem. Fourth, there were more publications on the integrated AHP approaches during the period from 2007 to 2016. It is also estimated that AHP integration with more than one method will attract more attention. Fifth, the International Journal of Production Research replaced the European Journal of Operational Research as the most commonly published journal. Finally, several new applications of new AHP integrations are recommended. These topics would assist scholars in filling the literature research gaps. 


\section{References}

Aguilar-Lasserre, A.A., Bautista Bautista, M.A., Ponsich, A., González Huerta, M.A., 2009. An AHPbased decision-making tool for the solution of multiproduct batch plant design problem under imprecise demand. Computers \& Operations Research 36 (3), 711-736.

Ahlatcioglu, M., Tiryaki, F., 2007. Interactive fuzzy programming for decentralized two-level linear fractional programming (DTLLFP) problems. Omega 35 (4), 432-450.

Ahn, B.S., Choi, S.H., 2008. ERP system selection using a simulation-based AHP approach: A case of Korean homeshopping company. Journal of the Operational Research Society 59 (3), 322-330.

Akarte, M.M., Ravi, B., 2007. Casting product-process-producer compatibility evaluation and improvement. International Journal of Production Research 45 (21), 4917-4936.

Angelou, G.N., Economides, A.A., 2008. A decision analysis framework for prioritizing a portfolio of ICT infrastructure projects. IEEE Transactions on Engineering Management 55 (3), 479-495.

Arslan, T., 2009. A hybrid model of fuzzy and AHP for handling public assessments on transportation projects. Transportation 36 (1), 97-112.

Avikal, S., Mishra, P.K., Jain, R., 2014. A fuzzy AHP and PROMETHEE method-based heuristic for disassembly line balancing problems. International Journal of Production Research 52 (5), 13061317.

Ayağ, Z., 2007. A hybrid approach to machine-tool selection through AHP and simulation. International Journal of Production Research 45 (9), 2029-2050.

Aznar, J., Guijarro, F., Moreno-Jiménez, J.M., 2011. Mixed valuation methods: A combined AHP-GP procedure for individual and group multicriteria agricultural valuation. Annals of Operations Research 190 (1), 221-238.

Babić, Z., Perić, T., 2014. Multiproduct vendor selection with volume discounts as the fuzzy multiobjective programming problem. International Journal of Production Research 52 (14), 43154331.

Bana e Costa, C.A., Vansnick, J.C., 2008. A critical analysis of the eigenvalue method used to derive priorities in AHP. European Journal of Operational Research 187 (3), 1422-1428.

Baramichai, M., Zimmers Jr., E.W., Marangos, C.A., 2007. Agile supply chain transformation matrix: An integrated tool for creating an agile enterprise. Supply Chain Management: An International Journal 12 (5), 334-348.

Belton, V., Gear, T., 1983. On a short-coming of Saaty’s method of analytic hierarchies. Omega 11 (3), 228-230.

Büyüközkan, G., 2012. An integrated fuzzy multi-criteria group decision-making approach for green supplier evaluation. International Journal of Production Research 50 (11), 2892-2909.

Büyüközkan, G., Feyzioğlu, O., Nebol, E., 2008. Selection of the strategic alliance partner in logistics value chain. International Journal of Production Economics 113 (1), 148-158.

Chan, F.T.S., Kumar, N., 2007. Global supplier development considering risk factors using fuzzy extended AHP-based approach. Omega 35 (4), 417-431.

Chan, F.T.S., Kumar, N., Tiwari, M.K., Lau, H.C.W., Choy, K.L., 2008. Global supplier selection: A fuzzy-AHP approach. International Journal of Production Research 46 (14), 3825-3857.

Chan, H.K., Wang, X., White, G.R.T., Yip, N., 2013. An extended fuzzy-AHP approach for the evaluation of green product designs. IEEE Transactions on Engineering Management 60 (2), 327339. 
Chang, A.Y., 2012. Prioritising the types of manufacturing flexibility in an uncertain environment. International Journal of Production Research 50 (8), 2133-2149.

Che, Z.H., Chiang, T.A., 2012. Designing a collaborative supply-chain plan using the analytic hierarchy process and genetic algorithm with cycle-time estimation. International Journal of Production Research 50 (6), 4426-4443.

Chiang, C.Y., Kocabasoglu-Hillmer, C., Suresh, N., 2012. An empirical investigation of the impact of strategic sourcing and flexibility on firm's supply chain agility. International Journal of Operations and Production Management 32 (1), 49-78.

Chu, M.T., Shyu, J.Z., Tzeng, G.H., Khosla, R., 2007. Using nonadditive fuzzy integral to assess performances of organizational transformation via communities of practice. IEEE Transactions on Engineering Management 54 (2), 327-339.

Dey, P.K., Bhattacharya, A., Ho, W., 2015. Strategic supplier performance evaluation: A case-based action research of a UK manufacturing organisation. International Journal of Production Economics 166, 192-214.

Dincer, H., Haciogle, U., Tatoglu, E., Delen, D., 2016. A fuzzy-hybrid analytic model to assess investors’ perceptions for industry selection. Decision Support Systems 86, 24-34.

Dong, Y., Hong, W.C., Xu, Y., Yu, S., 2013. Numerical scales generated individually for analytic hierarchy process. European Journal of Operational Research 229 (3), 654-662.

Ergu, D., Kou, G., Peng, Y., Shi, Y., 2011. A simple method to improve the consistency ratio of the pair-wise comparison matrix in AHP. European Journal of Operational Research 213 (1), 246259.

Falsini, D., Fondi, F., Schiraldi, M.M., 2012. A logistics provider evaluation and selection methodology based on AHP, DEA and linear programming integration. International Journal of Production Research 50 (17), 4822-4829.

Forman, E.H., 1993. Facts and fictions about the analytic hierarchy process. Mathematical and Computer Modelling 17 (4/5), 19-26.

Freeman, J., Chen, T., 2015. Green supplier selection using an AHP-Entropy-TOPSIS framework. Supply Chain Management: An International Journal 20 (3), 327-340.

Ghodsypour, S.H., O’Brien, C., 2001. The total cost of logistics in supplier selection, under conditions of multiple sourcing, multiple criteria and capacity constraint. International Journal of Production Economics 73 (1), 15-27.

Ghorbani, M., Arabzad, S.M., Shahin, A., 2013. A novel approach for supplier selection based on the Kano model and fuzzy MCDM. International Journal of Production Research 51 (8), 5469-5484.

Goffin, K., Lemke, F., Szwejczewski, M., 2006. An exploratory study of ‘close’ supplier-manufacturer relationships. Journal of Operations Management 24 (2), 189-209.

He, T., Ho, W., Lee, C.K.M., Xu, X., 2012. A fuzzy AHP based integer linear programming model for the multi-criteria transshipment problem. International Journal of Logistics Management 23 (1), 159-179.

Ho, W., 2008. Integrated analytic hierarchy process and its applications - A literature review. European Journal of Operational Research 186 (1), 211-228.

Ho, W., Dey, P.K., Lockström, M., 2011. Strategic sourcing: A combined QFD and AHP approach in manufacturing. Supply Chain Management: An International Journal 16 (6), 446-461. 
Ho, W., Zheng, T., Yildiz, H., Talluri, S., 2015. Supply chain risk management: A literature review. International Journal of Production Research 53 (16), 5031-5069.

Huang, C.C., Chu, P.Y., Chiang, Y.H., 2008. A fuzzy AHP application in government-sponsored R\&D project selection. Omega 36 (6), 1038-1052.

Huang, C.T., Yeh, T.M., Lin, W.T., Lee, B.T., 2009. A fuzzy AHP-based performance evaluation model for implementing SPC in the Taiwanese LCD industry. International Journal of Production Research 47 (18), 5163-5183.

Ishizaka, A., Labib, A., 2011. Review of the main development in the analytic hierarchy process. Expert Systems with Applications 38 (11), 14336-14345.

Ishizaka, A., Labib, A., 2014. A hybrid and integrated approach to evaluate and prevent disasters. Journal of the Operational Research Society 65 (10), 1475-1489.

Kahraman, C., Beskese, A., Kaya, I., 2010. Selection among ERP outsourcing alternatives using a fuzzy multi-criteria decision making methodology. International Journal of Production Research 48 (2), 547-566.

Kamvysi, K., Gotzamani, K., Andronikidis, A., Georgiou, A.C., 2014. Capturing and prioritizing students' requirements for course design by embedding Fuzzy-AHP and linear programming in QFD. European Journal of Operational Research 237 (3), 1083-1094.

Kengpol, A., 2008. Design of a decision support system to evaluate logistics distribution network in Greater Mekong Subregion Countries. International Journal of Production Economics 115 (2), 388-399.

Kengpol A., Tuammee S., 2016. The development of a decision support framework for a quantitative risk assessment in multimodal green logistics: An empirical study. International Journal of Production Research 54 (4), 1020-1038.

Kengpol, A., Tuammee, S., Tuominen, M., 2014. The development of a framework for route selection in multimodal transportation. International Journal of Logistics Management 25 (3), 581-610.

Kilic, H.S., Zaim, S., Delen, D., 2014. Development of a hybrid methodology for ERP system selection: The case of Turkish Airlines. Decision Support Systems 66, 82-92.

Korpela, J., Lehmusvaara, A., Nisonen, J., 2007. Warehouse operator selection by combining AHP and DEA methodologies. International Journal of Production Economics 108 (1-2), 135-142.

Kou, G., Ergu, D., Shang, J., 2014. Enhancing data consistency in decision matrix: Adapting Hadamard model to mitigate judgment contradiction. European Journal of Operational Research 236 (1), 261-271.

Kou, R.J., Lee, L.Y., Hu, T.L., 2010. Developing a supplier selection system through integrating fuzzy AHP and fuzzy DEA: A case study on an auto lighting system company in Taiwan. Production Planning \& Control 51(5), 468-484.

Kou, G., Lin, C., 2014. A cosine maximization method for the priority vector derivation in AHP. European Journal of Operational Research 235 (1), 225-232.

Kreng, V.B., Wu, C.Y., 2007. Evaluation of knowledge portal development tools using a fuzzy AHP approach: The case of Taiwanese stone industry. European Journal of Operational Research 176 (3), 1795-1810.

Kulakowski, K., 2015. Notes on order preservation and consistency in AHP. European Journal of Operational Research 245 (1), 333-337. 
Kull, T.J., Talluri, S., 2008. A supply risk reduction model using integrated multicriteria decision making. IEEE Transactions on Engineering Management 55 (3), 409-419.

Lee, A.H.I., 2009. A fuzzy AHP evaluation model for buyer-supplier relationships with the consideration of benefits, opportunities, costs and risks. International Journal of Production Research 47 (15), 4255-4280.

Li, J., Zhang, H.C., Gonzalez, M.A., Yu, S., 2008. A multi-objective fuzzy graph approach for modular formulation considering end-of-life issue. International Journal of Production Research 46 (14), 4011-4033.

Liang, Y.H., 2015. Performance measurement of interorganizational information systems in the supply chain. International Journal of Production Research 53 (18), 5484-5499.

Liberatore, M.J., Nydick, R.L., 2008. The analytical hierarchy process in medical and health care decision making: A literature review. European Journal of Operational Research 189 (1), 194207.

Lin, M.I., Lee, Y.D., Ho, T.N., 2011. Applying integrated DEA/AHP to evaluate the economic performance of local governments in China. European Journal of Operational Research 209 (2), 129-140.

Ma, M.Y., Chen, C.Y., Wu, F.G., 2007. A design decision-making support model for customized product color combination. Computers in Industry 58 (6), 504-518.

Mafakheri, F., Breton, M., Ghoniem, A., 2011. Supplier selection-order allocation: A two-stage multiple criteria dynamic programming approach. International Journal of Production Economics 132 (1), 52-57.

Maleki, H., Zahir, S., 2013. A comprehensive literature review of the rank reversal phenomenon in the analytic hierarchy process. Journal of Multi-Criteria Decision Analysis 20 (3-4), 141-155.

Meza, J.L.C., Yildirim, M.B., Masud, A.S.M., 2009. A multiobjective evolutionary programming algorithm and its applications to power generation expansion planning. IEEE Transactions on Systems, Man, and Cybernetics - Part A: Systems and Humans 39 (5), 1086-1096.

Millet, I., Saaty, T.L., 2000. On the relativity of relative measures - Accommodating both rank preservation and rank reversals in the AHP. European Journal of Operational Research 121 (1), 205-212.

Mirchedayatian, S.M., Sean, R.F., 2011. A new approach for weight derivation using data envelopment analysis in the analytic hierarchy process. Journal of the Operational Research Society 62 (8), 1585-1595.

Nagahanumaiah, Ravi, B., Mukherjee N.P., 2007. Rapid tooling manufacturability evaluation using fuzzy-AHP methodology. International Journal of Production Research 45 (5), 1161-1181.

Nagahanumaiah, Subburaj, K., Ravi, B., 2008. Computer aided rapid tooling process selection and manufacturability evaluation for injection mold development. Computers in Industry 59 (2-3), 262-276.

Narasimhan, R., Das, A., 1999. An empirical investigation of the contribution of strategic sourcing to manufacturing flexibilities and performance. Decision Sciences 30 (3), 683-718.

Partovi, F.Y., 2007. An analytical model of process choice in the chemical industry. International Journal of Production Economics 105 (1), 213-227. 
Piechnicki, A.S., Sola, A.V.H., Trojan, F., 2015. Decision-making towards achieving world-class total productive maintenance. International Journal of Operations \& Production Management 35 (12), 1594-1621.

Pitchipoo, P., Venkumar, P., Rajakarunakaran, S., 2013. Fuzzy hybrid decision model for supplier evaluation and selection. International Journal of Production Research 51 (13), 3903-3919.

Quezada, L.E., López-Ospina, H.A., 2014. A method for designing a strategy map using AHP and linear programming. International Journal of Production Economics 158, 244-255.

Rabelo, L., Eskandari, H., Shaalan, T., Helal M., 2007. Value chain analysis using hybrid simulation and AHP. International Journal of Production Economics 105(2), 536-547.

Rao, R.V., Patel, B.K., 2010. Decision making in the manufacturing environment using an improved PROMETHEE method. International Journal of Production Research 48 (16), 4665-4682.

Ray, A., Sarkar, B., Sanyal, S., 2010. The TOC-based algorithm for solving multiple constraint resources. IEEE Transactions on Engineering Management 57 (2), 301-209.

Ren, J., Lützen, M., 2015. Fuzzy multi-criteria decision-making method for technology selection for emissions reduction from shipping under uncertainties. Transportation Research Part D: Transport and Environment 40, 43-60.

Rezaei, J., Ortt, R., 2013. Multi-criteria supplier segmentation using a fuzzy preference relations based AHP. European Journal of Operational Research 225 (1), 75-84.

Saaty, T.L., 1994. Highlights and critical points in the theory and application of the Analytic Hierarchy Process. European Journal of Operational Research 74 (3), 426-447.

Saaty, T.L., 2013. The modern science of multicriteria decision making and its practical applications: The AHP/ANP approach. Operations Research 61 (5), 1101-1118.

Saaty, T.L., Shang, J.S., 2011. An innovative orders-of-magnitude approach to AHP-based multicriteria decision making: Prioritizing divergent intangible humane acts. European Journal of Operational Research 214 (3), 703-715.

Samvedi, A., Jain, V., Chan, F.T.S., 2012. An integrated approach for machine tool selection using fuzzy analytical hierarchy process and grey relational analysis. International Journal of Production Research 50 (12), 3211-3221.

Samvedi, A., Jain, V., Chan, F.T.S., 2013. Quantifying risks in a supply chain through integration of fuzzy AHP and fuzzy TOPSIS. International Journal of Production Research 51 (8), 2433-2442.

Sarfaraz, A., Jenab, K., D’Souza, A.C., 2012. Evaluating ERP implementation choices on the basis of customisation using fuzzy AHP. International Journal of Production Research 50 (23), 70577067.

Schenkerman, S., 1994. Avoiding ranking reversal in AHP decision-support models. European Journal of Operational Research 74 (3), 407-419.

Scott, J.A., Ho, W., Dey, P.K., 2013. Strategic sourcing in the UK bioenergy industry. International Journal of Production Economics 146 (2), 478-490.

Scott, J.A., Ho, W., Dey, P.K., Talluri, S., 2015. A decision support system for supplier selection and order allocation in stochastic, multi-stakeholder and multi-criteria environments. International Journal of Production Economics 166, 226-237.

Sevkli, M., Koh, S.C.L., Zaim, S., Demirbag, M., Tatoglu, E., 2007. An application of data envelopment analytic hierarchy process for supplier selection: A case study of BEKO in Turkey. International Journal of Production Research 45 (9), 1973-2003. 
Sharma, S., Agrawal, N., 2009. Selection of a pull production control policy under different demand situations for a manufacturing system by AHP-algorithm. Computers \& Operations Research 36 (5), 1622-1632.

Sipahi, S., Timor, M., 2010. The analytic hierarchy process and analytic network process: An overview of applications. Management Decision 48 (5), 775-808.

Song, W., Ming, X., Han, Y., Wu, Z., 2013. A rough set approach for evaluating vague customer requirement of industrial product-service system. International Journal of Production Research 51 (22), 6681-6701.

Su, J., Dyer, C.L., Gargeya, V.B., 2009. Strategic sourcing and supplier selection in the U.S. textileapparel-retail supply network. Clothing and Textiles Research Journal 27 (2), 83-97.

Subramanian, N., Ramanathan, R., 2012. A review of applications of analytic hierarchy process in operations management. International Journal of Production Economics 138 (2), 215-241.

Sueyoshi, T., Shang, J., Chiang, W.C., 2009. A decision support framework for internal audit prioritization in a rental car company: A combined use between DEA and AHP. European Journal of Operational Research 199 (1), 219-231.

Sun, Y.H., Ma, J., Fan, Z.P., Wang, J., 2008. A group decision support approach to evaluate experts for R\&D project selection. IEEE Transactions on Engineering Management 55 (1), 158-170.

Tsai, W.H., Hung, S.J., 2009a. Dynamic pricing and revenue management process in Internet retailing under uncertainty: An integrated real options approach. Omega 37 (2), 471-481.

Tsai, W.H., Hung, S.J., 2009b. A fuzzy goal programming approach for green supply chain optimisation under activity-based costing and performance evaluation with a value-chain structure. International Journal of Production Research 47 (18), 4991-5017.

Tseng, F.M., Chiu, Y.J., Chen, J.S., 2009. Measuring business performance in the high-tech manufacturing industry: A case study of Taiwan's large-sized TFT-LCD panel companies. Omega 37 (3), 686-697.

Ulutas, A., Shukla, N., Kiridena, S., Gibson, P., 2016. A utility-driven approach to supplier evaluation and selection: Empirical validation of an integrated solution framework. International Journal of Production Research 54 (5), 1554-1567.

Validi, S., Bhattacharya, A., Byrne, P.J., 2014. Integrated low-carbon distribution system for the demand side of a product distribution supply chain: A DoE-guided MOPSO optimiser-based solution approach. International Journal of Production Research 52 (10), 3074-3096.

van de Kaa, G., van Heck, E., de Vries, H. J., van den Ende, J., Rezaei, J., 2014. Supporting decision making in technology standards battles based on a fuzzy analytic hierarchy process. IEEE Transactions on Engineering Management 61 (2), 336-348.

Vargas, L.G., 1994. Reply to Schenkerman's avoiding ranking reversal in AHP decision support models. European Journal of Operational Research 74 (3), 420-425.

Wang, J.Q., Zhang Z.T., Chen J., Guo Y.Z., Wang S., Sun S.D., Qu T., Huang G.Q., 2014. The TOCbased algorithm for solving multiple constraint resources: A Re-examination. IEEE Transactions on Engineering Management 61 (1), 138-146.

Wang, L., Chu, J., Wu, J., 2007. Selection of optimum maintenance strategies based on a fuzzy analytic hierarchy process. International Journal of Production Economics 107 (1), 151-163. 
Wang, T.C., Chang, T.C., 2007. Application of consistent fuzzy preference relations in predicting the success of knowledge management implementation. European Journal of Operational Research 182 (3), 1313-1329.

Wang, X., Chan, H.K., Yee, R.W.Y., Diaz-Rainey, I., 2012. A two-stage fuzzy-AHP model for risk assessment of implementing green initiatives in the fashion supply chain. International Journal of Production Economics 135 (2), 595-606.

Wang, Y.M., Chin, K.S., 2009. A new data envelopment analysis method for priority determination and group decision making in the analytic hierarchy process. European Journal of Operational Research 195 (1), 239-250.

Wang, Y.M., Chin, K.S., Luo, Y., 2009. Aggregation of direct and indirect judgments in pairwise comparison matrices with a re-examination of the criticisms by Bana e Costa and Vansnick. Information Sciences 179 (3), 329-337.

Wang, Y.M., Chin, K.S., Poon, G.K.K., 2008. A data envelopment analysis method with assurance region for weight generation in the analytic hierarchy process. Omega 45 (4), 913-921.

Wang, Y.M., Elhag, T.M.S., 2006. An approach to avoiding rank reversal in AHP. Decision Support Systems 42 (3), 1474-1480.

Wang, Y.M., Luo, Y., Hua, Z., 2008. On the extent analysis method for fuzzy AHP and its applications. European Journal of Operational Research 186 (2), 735-747.

Yan, L.J., Li, Z.B., Xi, W.K., Yuan, X.Y., 2012. Group-based product scheme-screening decision method based on fuzzy AHP and evidential reasoning theory. International Journal of Production Research 50 (1), 133-159.

Yaraghi, N., Tabesh, P., Guan, P., Zhuang, J., 2015. Comparison of AHP and Monte Carlo AHP under different levels of uncertainty. IEEE Transactions on Engineering Management 62 (1), 122-132.

Yayla, A.Y., Oztekin, A., Gumus, A.T., Gunasekaran, A., 2015. A hybrid data analytic methodology for 3PL transportation provider evaluation using fuzzy multi-criteria decision making. International Journal of Production Research 53 (20), 6097-6113.

Yeo, G.T., Song, D.W., Dinwoodie, J., Roe, M., 2010. Weighting the competitiveness factors for container ports under conflicting interests. Journal of the Operational Research Society 61 (8), 1249-1257.

Zhang, X., Lee, C.K.M., Chen, S., 2012. Supplier evaluation and selection: A hybrid model based on DEAHP and ABC. International Journal of Production Research 50 (7), 1877-1889.

Zhou, Y., Chen, Y., 2010. The analytic supporting tools for business reengineering with system integration design. IEEE Transactions on Systems, Man, and Cybernetics - Part A: Systems and Humans 40 (2), 285-300.

Zhü K., Cooper O., Yang S.L., Dong Q.X., 2014. An extension of the AHP dummy pivot modelling applied to the restructuring of the iron and steel industry in China. IEEE Transactions on Engineering Management 61 (2), 370-380. 


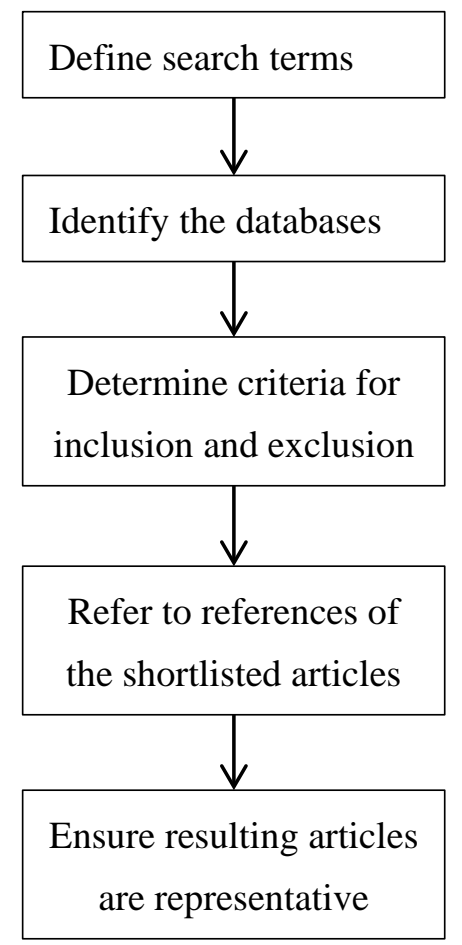

Figure 1. Flowchart of the research methodology. 
Table 1. The integrated AHP-fuzzy set theory approach and its applications

\begin{tabular}{|c|c|c|c|}
\hline Approach & Authors & Applications areas & Specific problems \\
\hline \multirow[t]{20}{*}{ AHP-fuzzy } & Akarte and Ravi (2007) & Steel casting manufacturing & Casting process and producer evaluation and selection \\
\hline & Chan and Kumar (2007) & General manufacturing & Supplier evaluation and selection \\
\hline & Chu et al. (2007) & Multiple industries & Organizational transformation performance assessment \\
\hline & Kreng and Wu (2007) & Stone manufacturing & Knowledge portal system evaluation and selection \\
\hline & Ma et al. (2007) & Furniture manufacturing & Sofa design evaluation and selection \\
\hline & Nagahanumaiah et al. (2007) & Mould manufacturing & Rapid tooling process evaluation and selection \\
\hline & Wang and Chang (2007) & LCD manufacturing & Knowledge management project evaluation and selection \\
\hline & Wang et al. (2007) & Thermal power & Maintenance strategy evaluation and selection \\
\hline & Chan et al. (2008) & General manufacturing & Supplier evaluation and selection \\
\hline & Huang et al. (2008) & Government & $\begin{array}{l}\text { Industrial technology development program evaluation } \\
\text { and selection }\end{array}$ \\
\hline & Wang et al. (2008) & Textiles and fashion & Catering firm evaluation and selection \\
\hline & Arslan (2009) & Government & Transportation project evaluation and selection \\
\hline & Huang et al. (2009) & LCD manufacturing & SPC implementation strategy evaluation and selection \\
\hline & Lee (2009) & LCD manufacturing & Supplier evaluation and selection \\
\hline & Kahraman et al. (2010) & Automotive & ERP supplier evaluation and selection \\
\hline & Sarfaraz et al. (2012) & General manufacturing & ERP customization technique evaluation and selection \\
\hline & Wang et al. (2012) & Textiles and fashion & Green initiative risk assessment \\
\hline & Rezaei and Ortt (2013) & Food & Supplier evaluation and selection \\
\hline & van de Kaa et al. (2014) & Telecommunications & Technology standard assessment \\
\hline & Liang (2015) & Telecommunications & Information system assessment \\
\hline Total & 20 & & \\
\hline
\end{tabular}


Table 2. The integrated AHP-DEA approach and its applications

\begin{tabular}{llll}
\hline Approach & Authors & Applications areas & Specific problems \\
\hline AHP-DEA & Korpela et al. (2007) & Process & Warehouse evaluation and selection \\
& Sevkli et al. (2007) & TV manufacturing & Supplier evaluation and selection \\
& Wang et al. (2008) & Higher education & Research fellow evaluation and selection \\
& Sueyoshi et al. (2009) & Rental cars & Critical business unit evaluation and selection \\
& Wang et al. (2009) & Higher education & University president evaluation and selection \\
& Lin et al. (2011) & Government & Economic performance assessment \\
& Mirhedayatian and Saen (2011) & Higher education & University president evaluation and selection \\
Total & 7 & & \\
\hline
\end{tabular}

Table 3. The integrated AHP-Mathematical programming approaches and their applications

\begin{tabular}{llll}
\hline Approaches & Authors & Applications areas & Specific problems \\
\hline AHP-GP & Kull and Talluri (2008) & Automotive & Supplier selection and order allocation \\
& Anzar et al. (2011) & Agricultural & Asset valuation \\
AHP-MILP & Kengpol (2008) & Logistics & Logistics distribution network optimization \\
& Validi et al. (2014) & Logistics & Low carbon distribution system optimization \\
AHP-DP & Mafakheri et al. (2011) & General manufacturing & Supplier selection and order allocation \\
AHP-LP & Ishizaka and Labib (2014) & Government & Disaster assessment and resource allocation \\
AHP-MOLP & Quezada and López-Ospina (2014) & Fishing & The cause-effect relationships within a strategy map \\
Total & 7 & & \\
\hline
\end{tabular}


Table 4. The integrated AHP-QFD approach and its applications

\begin{tabular}{llll}
\hline Approach & Authors & Application areas & Specific problems \\
\hline AHP-QFD & Baramichai et al. (2007) & Plastics manufacturing & Supply chain agility capabilities improvement \\
& Ho et al. (2011) & Automotive & Supplier evaluation and selection \\
& Scott et al. (2013) & Bioenergy & Supplier evaluation and selection \\
& Dey et al. (2015) & Carpet manufacturing & Supplier evaluation and selection \\
& Scott et al. (2015) & Bioenergy & Supplier evaluation and selection \\
Total & 5 & & \\
\hline
\end{tabular}

Table 5. The integrated AHP-simulation approach and its applications

\begin{tabular}{llll}
\hline Approach & Authors & Applications areas & Specific problems \\
\hline AHP-simulation & Ayağ (2007) & Cutting-tool manufacturing & Machine tool evaluation and selection \\
& Rabelo et al. (2007) & Construction & Value chain evaluation and selection \\
& Ahn and Choi (2008) & Internet retailing & ERP system evaluation and selection \\
& Sharma and Agrawal (2009) & General manufacturing & Production control policy evaluation and selection \\
& Yaraghi et al. (2015) & Internet & Blog ranking \\
Total & 5 & & \\
\hline
\end{tabular}


Table 6. The integrated AHP-Other approaches and their applications

\begin{tabular}{llll}
\hline Approaches & Authors & Applications areas & Specific problems \\
\hline AHP-RO & Angelou and Economides (2008) & Water supply and sewerage & ICT infrastructure project evaluation and selection \\
& Tsai and Hung (2009a) & Internet retailing & Dynamic pricing and revenue management \\
AHP-TOC & Ray et al. (2010) & Fabrication process & Product-mix evaluation and selection \\
& Wang et al. (2014) & Fabrication process & Product-mix evaluation and selection \\
AHP-2TLRM & Dong et al. (2013) & Government & Liveable city evaluation and selection \\
AHP-DST & Yeo et al. (2010) & Iron and steel & Container port competitiveness assessment \\
AHP-OM & Zhü et al. (2014) & Air compressor manufacturing & Location evaluation and selection \\
AHP-RST & Song et al. (2013) & & Product-service system requirement assessment \\
Total & 8 & &
\end{tabular}


Table 7. The integrated AHP-Multiple approaches and their applications

\begin{tabular}{|c|c|c|c|}
\hline Authors & Applications areas & Specific problems & Approaches \\
\hline Partovi (2007) & Chemicals & Manufacturing process evaluation and selection & AHP, ANP, QFD \\
\hline Büyüközkan et al. (2008) & Logistics & Supplier evaluation and selection & AHP, Fuzzy set theory, TOPSIS \\
\hline Li et al. (2008) & Electronics & Product design evaluation and selection & AHP, Fuzzy set theory, MOLP \\
\hline Nagahanumaiah et al. (2008) & Mould manufacturing & Rapid tooling process evaluation and selection & AHP, Fuzzy set theory, QFD \\
\hline Sun et al. (2008) & Higher education & External reviewer evaluation and selection & $\begin{array}{l}\text { AHP, Fuzzy set theory, Scoring } \\
\text { method }\end{array}$ \\
\hline Aguilar-Lasserre et al. (2009) & Chemicals & Batch plant design & AHP, Fuzzy set theory, GA \\
\hline Meza et al. (2009) & Renewable energy & Power generation expansion planning & $\begin{array}{l}\text { AHP, MOMILP, K-means } \\
\text { algorithm }\end{array}$ \\
\hline Tsai and Hung (2009b) & Telecommunications & Supplier evaluation and selection & AHP, Fuzzy set theory, GP \\
\hline Tseng et al. (2009) & LCD manufacturing & Business performance assessment & AHP, Fuzzy set theory, DEA \\
\hline Kou et al. (2010) & Automotive & Supplier evaluation and selection & AHP, Fuzzy set theory, DEA \\
\hline Rao and Patel (2010) & General manufacturing & Cutting fluid evaluation and selection & $\begin{array}{l}\text { AHP, Fuzzy set theory, } \\
\text { PROMETHEE }\end{array}$ \\
\hline Zhou and Chen (2010) & General manufacturing & Business process re-engineering & AHP, DEA, QFD \\
\hline Büyüközkan (2012) & Automotive & Supplier evaluation and selection & AHP, Fuzzy set theory, AD \\
\hline Chang (2012) & Food & $\begin{array}{l}\text { Manufacturing flexibility evaluation and } \\
\text { selection }\end{array}$ & AHP, QFD, GRA \\
\hline Che and Chiang (2012) & General manufacturing & Supplier evaluation and selection & AHP, MOP, GA, RST \\
\hline Falsini et al. (2012) & Logistics & Supplier evaluation and selection & AHP, LP, DEA \\
\hline He et al. (2012) & Logistics & Transshipment problem & AHP, Fuzzy set theory, ILP \\
\hline Samvedi et al. (2012) & Automotive & Machine tool evaluation and selection & AHP, Fuzzy set theory, GRA \\
\hline Yan et al. (2012) & Equipment manufacturing & Product design evaluation and selection & AHP, Fuzzy set theory, ERT \\
\hline Zhang et al. (2012) & Electronics & Supplier evaluation and selection & AHP, DEA, ABC \\
\hline Chan et al. (2013) & Electronics & Product design evaluation and selection & AHP, Fuzzy set theory, LCA \\
\hline
\end{tabular}


Ghorbani et al. (2013)

Pitcchipoo et al. (2013)

Samvedi et al. (2013)

Avikal et al. (2014)

Babić and Perić (2014)

Kamvysi et al. (2014)

Kengpol et al. (2014)

Kilic et al. (2014)

Freeman and Chen (2015)

Piechnicki et al. (2015)

Ren and Lützen (2015)

Yayla (2015)

Dincer et al. (2016)

Kengpol and Tuammee (2016)

Ulutas et al. (2016)

Total
Equipment manufacturing Supplier evaluation and selection

Electroplating process

Multiple industries

General manufacturing

Bakeries

Higher education

Logistics

Airline

Electronics

Multiple industries

Logistics

Logistics

Financial

Logistics

Textiles and fashion

36
Supplier evaluation and selection

Supply chain risk assessment

Disassembly line balancing

Supplier evaluation and selection

Course design evaluation and selection

Transportation route evaluation and selection ERP system evaluation and selection

Supplier evaluation and selection

Total productive maintenance design

Fuel evaluation and selection

Supplier evaluation and selection

Portfolio investment assessment

Transportation route evaluation and selection

Supplier selection and order allocation
AHP, Fuzzy set theory, TOPSIS,

Kano model

AHP, Fuzzy set theory, GRA

AHP, Fuzzy set theory, TOPSIS

AHP, Fuzzy set theory,

\section{PROMETHEE}

AHP, Fuzzy set theory, MOMILP

AHP, Fuzzy set theory, LP, DEA,

QFD

AHP, GP, DEA, QRA

AHP, Fuzzy set theory, TOPSIS

AHP, TOPSIS, Entropy

AHP, Fuzzy set theory, Geometric mean, Copeland

AHP, Fuzzy set theory, VIKOR

AHP, Fuzzy set theory, TOPSIS

AHP, Fuzzy set theory, TOPSIS

AHP, DEA, QRA

AHP, Fuzzy set theory, LP 
Table 8. Summary of methods (other than AHP) used in the integrated AHP-Multiple approaches

\begin{tabular}{|c|c|c|}
\hline Methods & Number of articles & Authors \\
\hline Fuzzy set theory & 26 & $\begin{array}{l}\text { Büyüközkan et al. (2008), Li et al. (2008), Nagahanumaiah et al. (2008), Sun et al. (2008), } \\
\text { Aguilar-Lasserre et al. (2009), Tsai and Hung (2009b), Tseng et al. (2009), Kou et al. (2010), } \\
\text { Rao and Patel (2010), Büyüközkan (2012), He et al. (2012), Samvedi et al. (2012), Yan et al. } \\
\text { (2012), Chan et al. (2013), Ghorbani et al. (2013), Pitcchipoo et al. (2013), Samvedi et al. } \\
\text { (2013), Avikal et al. (2014), Babić and Perić (2014), Kamvysi et al. (2014), Kilic et al. (2014), } \\
\text { Piechnicki et al. (2015), Ren and Lützen (2015), Yayla (2015), Dincer et al. (2016), Ulutas et } \\
\text { al. (2016) }\end{array}$ \\
\hline Mathematical programming & 10 & $\begin{array}{l}\text { Li et al. (2008), Meza et al. (2009), Tsai and Hung (2009b), Che and Chiang (2012), Falsini et } \\
\text { al. (2012), He et al. (2012), Babić and Perić (2014), Kamvysi et al. (2014), Kengpol et al. } \\
\text { (2014), Ulutas et al. (2016) }\end{array}$ \\
\hline DEA & 8 & $\begin{array}{l}\text { Tseng et al. (2009), Kou et al. (2010), Zhou and Chen (2010), Falsini et al. (2012), Zhang et } \\
\text { al. (2012), Kamvysi et al. (2014), Kengpol et al. (2014), Kengpol and Tuammee (2016) }\end{array}$ \\
\hline TOPSIS & 7 & $\begin{array}{l}\text { Büyüközkan et al. (2008), Ghorbani et al. (2013), Samvedi et al. (2013), Kilic et al. (2014), } \\
\text { Freeman and Chen (2015), Yayla (2015), Dincer et al. (2016) }\end{array}$ \\
\hline QFD & 5 & $\begin{array}{l}\text { Partovi (2007), Nagahanumaiah et al. (2008), Zhou and Chen (2010), Chang (2012), Kamvysi } \\
\text { et al. (2014) }\end{array}$ \\
\hline GRA & 3 & Chang (2012), Samvedi et al. (2012), Pitcchipoo et al. (2013) \\
\hline GA & 2 & Aguilar-Lasserre et al. (2009), Che and Chiang (2012) \\
\hline PROMETHEE & 2 & Rao and Patel (2010), Avikal et al. (2014) \\
\hline QRA & 2 & Kengpol et al. (2014), Kengpol and Tuammee (2016) \\
\hline $\mathrm{ABC}$ & 1 & Zhang et al. (2012) \\
\hline AD & 1 & Büyüközkan (2012) \\
\hline ANP & 1 & Partovi (2007) \\
\hline Copeland & 1 & Piechnicki et al. (2015) \\
\hline Entropy & 1 & Freeman and Chen (2015) \\
\hline
\end{tabular}


ERT

Geometric mean

K-means algorithm

Kano model

LCA

RST

Scoring method

VIKOR
Yan et al. (2012)

Piechnicki et al. (2015)

Meza et al. (2009)

Ghorbani et al. (2013)

Chan et al. (2013)

Che and Chiang (2012)

Sun et al. (2008)

Ren and Lützen (2015) 
Table 9. Summary of application areas

\begin{tabular}{|c|c|c|c|c|}
\hline Applications areas & Approaches & $\begin{array}{l}\text { Number of } \\
\text { articles }\end{array}$ & Sub-total & Authors \\
\hline \multirow[t]{19}{*}{ Manufacturing } & AHP-fuzzy & 11 & 35 & $\begin{array}{l}\text { Akarte and Ravi (2007), Chan and Kumar (2007), Kreng } \\
\text { and Wu (2007), Ma et al. (2007), Nagahanumaiah et al. } \\
\text { (2007), Wang and Chang (2007), Chan et al. (2008), Huang } \\
\text { et al. (2009), Lee (2009), Kahraman et al. (2010), Sarfaraz } \\
\text { et al. (2012) }\end{array}$ \\
\hline & AHP-QFD & 3 & & Baramichai et al. (2007), Ho et al. (2011), Dey et al. (2015) \\
\hline & AHP-simulation & 2 & & Ayağ (2007), Sharma and Agrawal (2009) \\
\hline & AHP, Fuzzy set theory, DEA & 2 & & Tseng et al. (2009), Kou et al. (2010) \\
\hline & AHP, Fuzzy set theory, PROMETHEE & 2 & & Rao and Patel (2010), Avikal et al. (2014) \\
\hline & AHP-DEA & 1 & & Sevkli et al. (2007) \\
\hline & AHP-DP & 1 & & Mafakheri et al. (2011) \\
\hline & AHP-GP & 1 & & Kull and Talluri (2008) \\
\hline & AHP-RST & 1 & & Song et al. (2013) \\
\hline & AHP, Fuzzy set theory, AD & 1 & & Büyüközkan (2012) \\
\hline & AHP, Fuzzy set theory, ERT & 1 & & Yan et al. (2012) \\
\hline & AHP, Fuzzy set theory, GRA & 1 & & Samvedi et al. (2012) \\
\hline & AHP, Fuzzy set theory, LCA & 1 & & Chan et al. (2013) \\
\hline & AHP, Fuzzy set theory, MOLP & 1 & & Li et al. (2008) \\
\hline & AHP, Fuzzy set theory, QFD & 1 & & Nagahanumaiah et al. (2008) \\
\hline & $\begin{array}{l}\text { AHP, Fuzzy set theory, TOPSIS, Kano } \\
\text { model }\end{array}$ & 1 & & Ghorbani et al. (2013) \\
\hline & AHP, DEA, ABC & 1 & & Zhang et al. (2012) \\
\hline & AHP, DEA, QFD & 1 & & Zhou and Chen (2010) \\
\hline & AHP, MOP, GA, RST & 1 & & Che and Chiang (2012) \\
\hline
\end{tabular}




$\begin{array}{ll} & \text { AHP, TOPSIS, Entropy } \\ \text { Logistics } & \text { AHP-MILP } \\ & \text { AHP, Fuzzy set theory, TOPSIS } \\ & \text { AHP-DST } \\ & \text { AHP, Fuzzy set theory, ILP } \\ & \text { AHP, Fuzzy set theory, VIKOR } \\ & \text { AHP, DEA, QRA } \\ & \text { AHP, GP, DEA, QRA } \\ & \text { AHP, LP, DEA } \\ & \text { AHP-fuzzy } \\ \text { Government } & \text { AHP-DEA } \\ & \text { AHP-LP } \\ & \text { AHP-2TLRM } \\ \text { Higher education } & \text { AHP-DEA } \\ & \text { AHP, Fuzzy set theory, LP, DEA, QFD } \\ \text { AHP, Fuzzy set theory, Scoring method } \\ \text { Ttility } & \text { AHP-QFD } \\ & \text { AHP-fuzzy } \\ \text { Internet } & \text { AHP-RO } \\ & \text { AHP, MOMILP, K-means algorithm } \\ \text { PHP-TOC } & \text { AHP-DEA } \\ \text { PHocess } & \text { AHP, Fuzzy set theory, GRA } \\ & \text { AHP-simulation } \\ & \text { AHP-RO } \\ & \text { AHP-fuzzy } \\ & \end{array}$

Freeman and Chen (2015)

Kengpol (2008), Validi et al. (2014)

Büyüközkan et al. (2008), Yayla (2015)

Yeo et al. (2010)

He et al. (2012)

Ren and Lützen (2015)

Kengpol and Tuammee (2016)

Kengpol et al. (2014)

Falsini et al. (2012)

$5 \quad$ Huang et al. (2008), Arslan (2009)

Lin et al. (2011)

Ishizaka and Labib (2014)

Dong et al. (2013)

$5 \quad$ Wang et al. (2008), Wang et al. (2009), Mirhedayatian and Saen (2011)

Kamvysi et al. (2014)

Sun et al. (2008)

$5 \quad$ Scott et al. (2013), Scott et al. (2015)

Wang et al. (2007)

Angelou and Economides (2008)

Meza et al. (2009)

$4 \quad$ Ray et al. (2010), Wang et al. (2014)

Korpela et al. (2007)

Pitcchipoo et al. (2013)

Ahn and Choi (2008), Yaraghi et al. (2015)

Tsai and Hung (2009a) 
AHP, Fuzzy set theory, GP

Textiles and fashion

AHP-fuzzy

AHP, Fuzzy set theory, LP

Chemicals

Food

Agricultural

Airlines

Bakeries

Construction

Financial

Fishing

Iron and steel

Rental cars

Multiple industries
AHP, ANP, QFD

AHP, Fuzzy set theory, GA

AHP-fuzzy

AHP, QFD, GRA

AHP-GP

AHP, Fuzzy set theory, TOPSIS

AHP, Fuzzy set theory, MOMILP

AHP-simulation

AHP, Fuzzy set theory, TOPSIS

AHP-MOLP

AHP-OM

AHP-DEA

AHP-fuzzy

AHP, Fuzzy set theory, Geometric

mean, Copeland

AHP, Fuzzy set theory, TOPSIS
Tsai and Hung (2009b)

Wang et al. (2008), Wang et al. (2012)

Ulutas et al. (2016)

Partovi (2007)

Aguilar-Lasserre et al. (2009)

Rezaei and Ortt (2013)

Chang (2012)

Anzar et al. (2011)

Kilic et al. (2014)

Babić and Perić (2014)

Rabelo et al. (2007)

Dincer et al. (2016)

Quezada and López-Ospina (2014)

Zhü et al. (2014)

Sueyoshi et al. (2009)

Chu et al. (2007)

Piechnicki et al. (2015)

Samvedi et al. (2013) 
Table 10. Summary of specific problems

\begin{tabular}{|c|c|c|c|c|}
\hline Specific problems & Approaches & $\begin{array}{l}\text { Number of } \\
\text { articles }\end{array}$ & Sub-total & Authors \\
\hline \multirow[t]{20}{*}{ Supplier evaluation and selection } & AHP-fuzzy & 6 & 26 & Chan and Kumar (2007), Chan et al. (2008), \\
\hline & & & & $\begin{array}{l}\text { Wang et al. (2008), Lee (2009), Kahraman et } \\
\text { al. (2010), Rezaei and Ortt (2013) }\end{array}$ \\
\hline & AHP-QFD & 4 & & $\begin{array}{l}\text { Ho et al. (2011), Scott et al. (2013), Dey et al. } \\
\text { (2015), Scott et al. (2015) }\end{array}$ \\
\hline & $\begin{array}{l}\text { AHP, Fuzzy set theory, } \\
\text { TOPSIS }\end{array}$ & 2 & & Büyüközkan et al. (2008), Yayla (2015) \\
\hline & AHP-DEA & 1 & & Sevkli et al. (2007) \\
\hline & AHP-DP & 1 & & Mafakheri et al. (2011) \\
\hline & AHP-GP & 1 & & Kull and Talluri (2008) \\
\hline & AHP, Fuzzy set theory, AD & 1 & & Büyüközkan (2012) \\
\hline & AHP, Fuzzy set theory, DEA & 1 & & Kou et al. (2010) \\
\hline & AHP, Fuzzy set theory, GP & 1 & & Tsai and Hung (2009b) \\
\hline & AHP, Fuzzy set theory, GRA & 1 & & Pitcchipoo et al. (2013) \\
\hline & AHP, Fuzzy set theory, LP & 1 & & Ulutas et al. (2016) \\
\hline & AHP, Fuzzy set theory, & 1 & & Babić and Perić (2014) \\
\hline & MOMILP & & & \\
\hline & AHP, Fuzzy set theory, & 1 & & Ghorbani et al. (2013) \\
\hline & TOPSIS, Kano model & & & \\
\hline & AHP, DEA, ABC & 1 & & Zhang et al. (2012) \\
\hline & AHP, LP, DEA & 1 & & Falsini et al. (2012) \\
\hline & AHP, MOP, GA, RST & 1 & & Che and Chiang (2012) \\
\hline & AHP, TOPSIS, Entropy & 1 & & Freeman and Chen (2015) \\
\hline
\end{tabular}


Performance assessment

AHP-fuzzy

AHP-DEA

AHP-GP

AHP-simulation

AHP-DST

AHP-RST

AHP, Fuzzy set theory, DEA

AHP, Fuzzy set theory,

TOPSIS

Strategy/policy evaluation and selection

Distribution network optimization

Process evaluation and selection
AHP-fuzzy

AHP-MOLP

AHP-QFD

AHP-simulation

AHP, Fuzzy set theory,

Geometric mean, Copeland

AHP, QFD, GRA

AHP-MILP

AHP, Fuzzy set theory, ILP

AHP, GP, DEA, QRA

AHP, DEA, QRA

AHP-fuzzy

AHP, Fuzzy set theory, QFD

AHP, DEA, QFD

AHP, ANP, QFD
Chu et al. (2007), van de Kaa et al. (2014),

Liang (2015)

Lin et al. (2011)

Anzar et al. (2011)

Yaraghi et al. (2015)

Yeo et al. (2010)

Song et al. (2013)

Tseng et al. (2009)

Dincer et al. (2016)

Wang et al. (2007), Huang et al. (2009),

Sarfaraz et al. (2012)

Quezada and López-Ospina (2014)

Baramichai et al. (2007)

Sharma and Agrawal (2009)

Piechnicki et al. (2015)

Chang (2012)

Kengpol (2008), Validi et al. (2014)

He et al. (2012)

Kengpol et al. (2014)

Kengpol and Tuammee (2016)

Akarte and Ravi (2007), Nagahanumaiah et al. (2007)

Nagahanumaiah et al. (2008)

Zhou and Chen (2010)

Partovi (2007) 
Expert evaluation and selection

AHP-DEA

AHP, Fuzzy set theory,

1

Scoring method

Product design evaluation and selection

Project/program evaluation and selection

Equipment/tool evaluation and selection

Location evaluation and selection

Risk assessment

System evaluation and selection

Product-mix evaluation and selection
AHP-fuzzy

AHP, Fuzzy set theory, ERT

AHP, Fuzzy set theory, LCA

AHP, Fuzzy set theory, MOLP 1

AHP-fuzzy

AHP-RO

AHP-simulation

AHP, Fuzzy set theory, GRA

AHP, Fuzzy set theory,

PROMETHEE

AHP-DEA

AHP-2TLRM

AHP-OM

AHP-fuzzy

AHP-LP

AHP, Fuzzy set theory,

TOPSIS

AHP-fuzzy

AHP-simulation

AHP, Fuzzy set theory,

TOPSIS

AHP-TOC
Mirhedayatian and Saen (2011)

Sun et al. (2008)

Ma et al. (2007)

Yan et al. (2012)

Chan et al. (2013)

Li et al. (2008)

Wang and Chang (2007), Huang et al. (2008),

Arslan (2009)

Angelou and Economides (2008)

Ayağ (2007)

Samvedi et al. (2012)

Rao and Patel (2010)

Korpela et al. (2007)

Dong et al. (2013)

Zhü et al. (2014)

Wang et al. (2012)

Ishizaka and Labib (2014)

Samvedi et al. (2013)

Kreng and Wu (2007)

Ahn and Choi (2008)

Kilic et al. (2014)

Ray et al. (2010), Wang et al. (2014) 
Batch plant design

Business unit evaluation and selection

Course design evaluation and selection

Disassembly line balancing

Dynamic pricing and revenue management

Fuel evaluation and selection

Power generation expansion planning

Value chain evaluation and selection

Total
AHP, Fuzzy set theory, GA

AHP-DEA

AHP, Fuzzy set theory, LP,

DEA, QFD

AHP, Fuzzy set theory,

PROMETHEE

AHP-RO

AHP, Fuzzy set theory,

VIKOR

AHP, MOMILP, K-means

algorithm

AHP-simulation
Aguilar-Lasserre et al. (2009)

Sueyoshi et al. (2009)

Kamvysi et al. (2014)

Avikal et al. (2014)

Tsai and Hung (2009a)

Ren and Lützen (2015)

Meza et al. (2009)

Rabelo et al. (2007) 
Table 11. Distribution of number of journal articles over the last 10 years

\begin{tabular}{cccc}
\hline \multicolumn{3}{c}{ Number of articles } \\
Years & Integration with one method & Integration with multiple methods & Total \\
\hline 2007 & 13 & 1 & 14 \\
2008 & 8 & 4 & 12 \\
2009 & 7 & 4 & 11 \\
2010 & 3 & 3 & 6 \\
2011 & 5 & 0 & 5 \\
2012 & 2 & 8 & 10 \\
2013 & 4 & 4 & 8 \\
2014 & 6 & 5 & 11 \\
2015 & 4 & 4 & 8 \\
2016 & 0 & 3 & 3 \\
\hline Total & 52 & 36 & 88 \\
\hline
\end{tabular}


Table 12. Summary of journals

\begin{tabular}{|c|c|c|}
\hline Journals & Number of articles & Authors \\
\hline International Journal of Production Research & 30 & $\begin{array}{l}\text { Akarte and Ravi (2007), Ayağ (2007), Nagahanumaiah et al. (2007), } \\
\text { Sevkli et al. (2007), Chan et al. (2008), Li et al. (2008), Huang et al. } \\
\text { (2009), Lee (2009), Tsai and Hung (2009b), Kahraman et al. (2010), } \\
\text { Rao and Patel (2010), Büyüközkan (2012), Chang (2012), Che and } \\
\text { Chiang (2012), Falsini et al. (2012), Samvedi et al. (2012), Sarfaraz et } \\
\text { al. (2012), Yan et al. (2012), Zhang et al. (2012), Ghorbani et al. } \\
\text { (2013), Pitcchipoo et al. (2013), Samvedi et al. (2013), Song et al. } \\
\text { (2013), Avikal et al. (2014), Babić and Perić (2014), Validi et al. } \\
\text { (2014), Liang (2015), Yayla (2015), Kengpol and Tuammee (2016), } \\
\text { Ulutas et al. (2016) }\end{array}$ \\
\hline International Journal of Production Economics & 12 & $\begin{array}{l}\text { Korpela et al. (2007), Partovi (2007), Rabelo et al. (2007), Wang et al. } \\
\text { (2007), Büyüközkan et al. (2008), Kengpol (2008), Mafakheri et al. } \\
\text { (2011), Wang et al. (2012), Scott et al. (2013), Quezada and López- } \\
\text { Ospina (2014), Dey et al. (2015), Scott et al. (2015) }\end{array}$ \\
\hline IEEE Transactions on Engineering Management & 10 & $\begin{array}{l}\text { Chu et al. (2007), Angelou and Economides (2008), Kull and Talluri } \\
\text { (2008), Sun et al. (2008), Ray et al. (2010), Chan et al. (2013), van de } \\
\text { Kaa et al. (2014), Wang et al. (2014), Zhü et al. (2014), Yaraghi et al. } \\
\text { (2015) }\end{array}$ \\
\hline European Journal of Operational Research & 9 & $\begin{array}{l}\text { Kreng and Wu (2007), Wang and Chang (2007), Wang et al. (2008), } \\
\text { Sueyoshi et al. (2009), Wang et al. (2009), Lin et al. (2011), Dong et al. } \\
\text { (2013), Rezaei and Ortt (2013), Kamvysi et al. (2014) }\end{array}$ \\
\hline Omega & 4 & $\begin{array}{l}\text { Chan and Kumar (2007), Huang et al. (2008), Tsai and Hung (2009a), } \\
\text { Tseng et al. (2009), }\end{array}$ \\
\hline Journal of the Operational Research Society & 4 & $\begin{array}{l}\text { Ahn and Choi (2008), Yeo et al. (2010), Mirhedayatian and Saen } \\
\text { (2011), Ishizaka and Labib (2014) }\end{array}$ \\
\hline
\end{tabular}


Decision Support Systems

Supply Chain Management: An International Journal 3

Computers \& Operations Research 2

Computers in Industry

IEEE Transactions on Systems, Man, and

Cybernetics - Part A: Systems and Humans

International Journal of Logistics Management

Annals of Operations Research

International Journal of Operations \& Production

Management

Production Planning \& Control

Transportation

Transportation Research Part D: Transport and Environment

Total
Wang et al. (2008), Kilic et al. (2014), Dincer et al. (2016)

Baramichai et al. (2007), Ho et al. (2011), Freeman and Chen (2015)

Aguilar-Lasserre et al. (2009), Sharma and Agrawal (2009)

Ma et al. (2007), Nagahanumaiah et al. (2008)

Meza et al. (2009), Zhou and Chen (2010)

He et al. (2012), Kengpol et al. (2014)

Anzar et al. (2011)

Piechnicki et al. (2015)

Kou et al. (2010)

Arslan (2009)

Ren and Lützen (2015) 